\title{
Identification, Isolation and Characterization of Poly-Hydroxy Butyrate (PHB) Producing Bacteria, and Extraction of the PHB Granules
}

\author{
Ananya V, Pradeek P, Vaishnavi G, Esther Shoba R1* \\ Department of Life Sciences, Kristu Jayanti College (Autonomous), K. Narayanapura, Kothanur (PO), \\ Bengaluru-560077 \\ Corresponding Author*: esther@kristujayanti.com
}

\begin{abstract}
Plastics, a non-renewable and non-degradable material have become one of the reasons for health crisis. Negative impact of plastic use on wild life and human health looks for an alternate that meets the requirement of human needs and also reduce the nuisance caused to the nature. Plastics that are bio based and degradable and similar to the properties of synthetic plastic is the solution to the problem and are termed as bio-plastics. In the present work, an attempt was made to isolate polyhydroxy butyrate (PHB) producing microorganisms from two different samples, garage soil sample and root nodules of Trigonella foenum-graecum leaves. The study also focused on the optimizing cultural conditions for the two isolated and identified PHB producing microorganisms, Bacillus subtillis and Pseudomonas aeruginosa by changing the parameters, viz., incubation time, $\mathrm{pH}$, carbon source and nitrogen source. Maximum PHB was obtained when the media was supplemented with Glucose as Carbon source for both Pseudomonas aeruginosa and Bacillus subtilis, Ammonium nitrate as Nitrogen source for Pseudomonas aeruginosa and Urea for Bacillus subtilis. The optimum $\mathrm{pH}$ was found to be $\mathrm{pH}$ 7 for both Pseudomonas aeruginosa and Bacillus subtilis and the optimum temperature was found to be $37^{\circ} \mathrm{C}$ for Pseudomonas aeruginosa and $30^{\circ} \mathrm{C}$ for Bacillus subtilis. The study also showed that Pseudomonas aeruginosa yields more PHB than Bacillus subtilis in comparison.
\end{abstract}

Keywords: Bioplastics, Bacillus subtilis, Pseudmonas aeruginosa, optimization

\section{Introduction}

The widely used material in modern days is plastic as the world produces more than 380 million tonnes of plastic every year. Since ages, approximately 1600 BC humans have been benefited from the polymers in the form of plates, tubes, fibers, plates, bottles, boxes and more. It is also used in every aspect like food packaging, textile industry, pharmaceutical packaging etc. Chemical nature of plastic is polymers of carbon, hydrogen, oxygen and/or silicon. On the contrary plastic is a nonrenewable and non-degradable material. Low tolerance to heat, poor ductility, combustibility and embrittlement are the adverse nature of the plastics. With more use of plastic for day to day activities, accumulation of plastic as waste has led to environmental problems such as air pollution, land pollution and water pollution. As of 2015 , of the approximately $6,300 \mathrm{Mt}$ of plastic waste generated, around 9 percent had been recycled, 12 percent incinerated, and 79 percent accumulated in landfills or the natural environment (1). To clear the menace of plastics, it is burnt. The Municipal Solid Waste (MSW) containing about $10-12 \%$ of plastic is burnt, releasing toxic gases into the environment which include substances like Dioxins, Furans, Mercury and Polychlorinated biphenyls (2). Buoyancy nature of plastics makes them float on the water surface and about 269,000 tons of plastic are seen on the surface waters across the world (3). Plastic waste affects wild life in the form of entanglement, ingestion and interaction. Plastic ingestion by swallowing from surrounding water or through consumption of organisms that have previously ingested plastics has an intense effect on metabolic rate, reduced reproducibility, reduced growth and development and reduced energy stores. For human health, the micro and nano particles of plastic on ingestion are responsible for cardiovascular, renal, gastrointestinal, neurological, reproductive, and respiratory systems, impacts that include cancers, diabetes, neuro, reproductive, and developmental toxicity. Negative impact of plastic use on wild life and human health looks for an alternate that meets the requirement of human needs and also reduce the nuisance caused to the nature. Plastics obtained from organisms and that can be degraded is the solution to the problem plastic is the solution to the problem and are termed as bio-plastics. Bioplastics are made from a variety of sources like polysaccharides, lipids and also proteins $(4,5$, and 6$)$. The main candidates for the large-scale production of PHAs are plants and bacteria. The sources for the bioplastics are plants and microorganisms. The first microbial plastic polyhydroxy butyrate $(\mathrm{PHB})$ is from Bacillus megaterium (7).

Accumulating PHAs is a natural way for bacteria to store carbon and energy, when nutrient supplies are imbalanced. These polyesters are accumulated when bacterial growth is limited by depletion of nitrogen, phosphorus or oxygen and an excess amount of a carbon source is still present (8). As PHAs are insoluble in water, the polymers are accumulated in intracellular granules inside the cells. It is advantageous for bacteria to store excess nutrients inside their cells, especially as their general physiological fitness is not affected (9). The increasing damage to the environment due to the 
usage of plastics is disturbing and the fact that plastics have become an integral part of our lives. Even though recycling, reusing and alternative usage other than plastic have been adopted, there are certain divisions where plastics are important for packaging and storing. So instead of using synthetic plastics when a group of microorganisms can produce biopolymers interested us to know more about the same. The aim of this study was to identify and isolate PHB producing bacteria from our surrounding environment and extract the granules.

\section{Materials and Methods}

\section{SAMPLE COLLECTION}

Soil samples were used for the isolation of $\mathrm{PHB}$ producing microorganisms. Soil Sample A (SS-A) was collected from a garage near Kristu Jayanti College, Bengaluru on 16thDecember 2019. Sample B (S-B) was from the root nodules of Methi leaves also called as Trigonella foenum-graecum $L$. purchased on 6th January 2020.

\section{ISOLATION OF PURE CULTURES}

Isolation of microorganisms was done by serial dilution method and $10^{-5}$ dilution was used. Dissemination of $100 \mu$ liluted samples on nutrient agar plates followed. Afterwards, the plates were incubated for 48 hours at $30^{\circ} \mathrm{C}$. Colonies with distinct characteristics were selected and purified by repeated streaking on identical LB agar plates.

\section{PRIMARY SCREENING OF PHB PRODUCING BACTERIA}

Primary screening of PHB producing bacteria was done using 2 methods. Lipophilic stain Sudan Black B staining that can be picked up by $\mathrm{PHB}$ producing colonies was used to detect PHB development. The second method was staining of the colonial smears with $0.3 \%$ Sudan Black B solution staining for 15 minutes followed by immersion in xylene and counterstain with safranin.

\section{SCREENING TECHNIQUES}

Twenty four hours old cultures of colonies were gram stained and the slide was observed under microscope for colony characterization and gram reaction.

\section{6s rRNA MICROBIAL IDENTIFICATION}

Two colonies were selected based on colony characterization and gram reaction and 16s rRNA partial sequencing was done using applied biosystems in Bangalore.

\section{OPTIMIZATION OF PHYSICAL PARAMETERS FOR MAXIMUM BACTERIAL GROWTH}

\section{Effect of $\mathrm{pH}$ on bacterial growth}

Every microorganism has a minimum, an optimum and a maximum $\mathrm{pH}$ for growth. To standardize the optimum $\mathrm{pH}$ for the production of $\mathrm{PHB}$, the $\mathrm{PHB}$ positive bacterial cultures were inoculated in $\mathrm{PHB}$ producing media - Minimal Davis Broth and maintained at different $\mathrm{pH}(3,5,7,9$ and 11$)$ and incubated at $37^{\circ} \mathrm{C}$ for 48 hours with occasional shaking. After incubation, turbidity of the media due to bacterial growth was measured by spectrophotometer at $640 \mathrm{~nm}$.

\section{Effect of temperature on bacterial growth}

Bacterial culture was inoculated in Minimal Davis Broth and incubated at different temperatures viz., $25^{\circ} \mathrm{C}, 30^{\circ} \mathrm{C}, 37^{\circ} \mathrm{C}$, and $40^{\circ} \mathrm{C}, 45^{\circ} \mathrm{C}$ for 48 hours days. After incubation the growth of cultures in the media was measured using spectrophotometer at $640 \mathrm{~nm}$.

Following optimization all the samples were screened using Sudan stain to confirm the development of PHB.

\section{OPTIMIZATION OF CULTURAL PARAMETERS FOR MAXIMUM PHB PRODUCTION}

$\mathrm{PHB}$, a polyester synthesized as energy reserve materials by various microorganisms under unfavorable conditions can accumulate more during stress conditions. In order to standardize the optimum carbon and nitrogen for PHB growth, PHB positive bacterial cultures were inoculated in PHB producing media [Minimal Davis Broth] and incubated for 48 hours at $37^{\circ} \mathrm{C}$ in shaker.

\section{Effect of carbon sources on PHB production:}

Positive bacterial isolates were grown in $250 \mathrm{ml}$ conical flasks containing $100 \mathrm{ml}$ Minimal Davis Broth with different carbon sources like glucose, fructose and maltose $(1 \%)$. The flasks were incubated at $37^{\circ} \mathrm{C}$ on a rotary shaker (150 rpm) for 48 hours. After incubation, PHB produced by the isolates were extracted by HYPOCHLORITE -CHLOROFORM METHOD explained below and quantified.

\section{EXTRACTION OF PHB}

\section{HYPOCHLORITE -CHLOROFORM METHOD}

The optimized $\mathrm{pH}$ and carbon source for positive bacterial cultures were used for the extraction of PHB by solvent extraction method $(10,13)$ with slight modifications. Firstly, $1 \%$ of $\mathrm{PHB}$ positive strain was inoculated in $\mathrm{PHB}$ producing media of optimized $\mathrm{pH}$ and carbon source and it was incubated at $37^{\circ} \mathrm{C}$. $40 \mathrm{ml}$ of 48 hour bacterial culture in Davis broth was taken and pelletized at $6000 \mathrm{rpm}$ for 20 minutes. For the recovery of $\mathrm{PHB}, 25 \mathrm{ml}$ of $4 \%$ sodium hypochlorite was used to resuspend the pellet it was incubated at $37^{\circ} \mathrm{C}$ for 1 hour. This was followed by centrifugation at $10000 \mathrm{rpm}$ for 10 minute to sediment the lipid granules. The bottom phase obtained was washed with acetone and ethanol $(1: 1)$ and $2.5 \mathrm{ml}$ of hot chloroform was added. Finally, the precipitate was evaporated in a hot air oven at $37^{\circ} \mathrm{C}$ kept in watch glass for PHB crystallization. 


\section{Effect of Nitrogen Sources on PHB production:}

Positive bacterial isolates were grown in $250 \mathrm{ml}$ conical flasks containing $100 \mathrm{ml}$ Minimal Davis Broth with different nitrogen sources like urea, ammonium nitrate and caesin all at $1 \%$ concentration. After incubation, PHB yields were extracted and quantified.

\section{MEDIA FORMULATION}

The optimized source of carbon, nitrogen, and physical parameter viz., $\mathrm{pH}$ ant temperature was formulated along with the minimal Davis Broth for PHB production using the two isolated, screened and identified microorganism and the PHB was extracted and quantified.

\section{RESULTS:}

\section{PRIMARY SCREENING OF PHB PRODUCING BACTERIA}

About 40 colonies from sample SS-A and S-B, which were distinct, were chosen based on their shapes and colors. After 24-48 hours culture period, each colony was sub cultured separately and the plates when flooded with Sudan Black B stain the colonies which took up the stain was screened. Among 40 bacteria , 5 were found to be Sudan positive ( 1 from SS-A and 4 from S-B) (Figure 1)and on the second method of detection by colonial smears with $0.3 \%$ Sudan Black B solution staining the Purple to black granules were observed inside the cells with pink background indicating further confirmation (Figure 2).

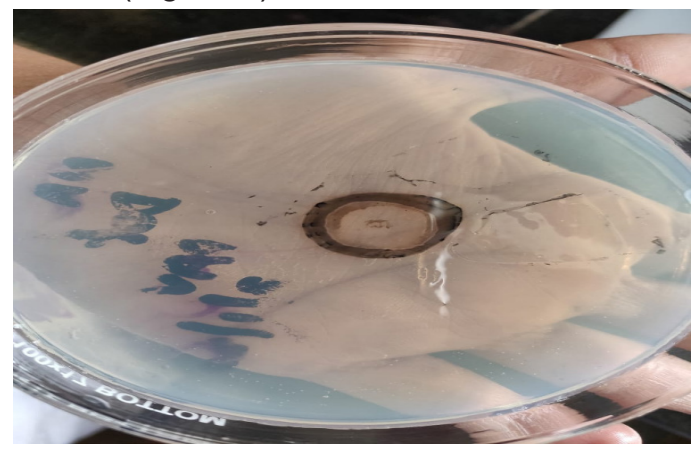

Figure 1: Colonies taking Sudan Black staining - PHB production

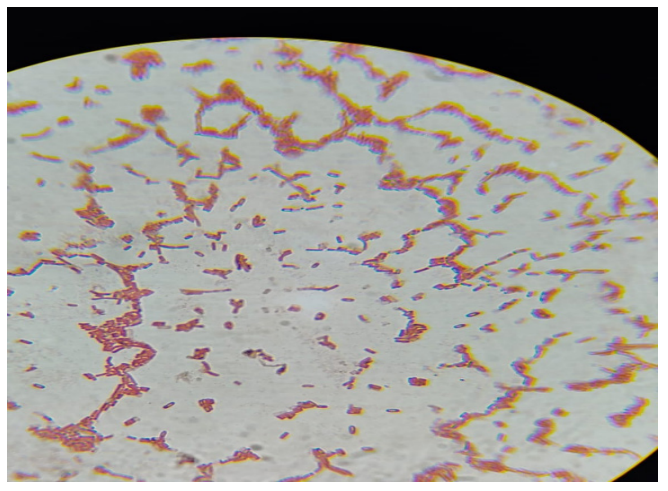

Figure 2: Observation of Purple to black granules after staining with Sudan Black B staining

\section{SCREENING TECHNIQUES}

On gram staining, colony from SS-A was found to be gram negative rods (SS-A-1) and all 4 PHB positive colonies were gram positive. For further studies, one gram positive and gram negative microorganism from each sample was selected. Colony characterizations of the 2 colonies are tabulated in Table 1.

Table1: Colony characterization of the positive colonies SS-A-1 and S-B-2

\begin{tabular}{|c|c|c|}
\hline Characteristics & SS-A-1 & S-B -2 \\
\hline Gram Staining & Gram negative & Gram positive \\
\hline Colony Shape & Circular & Circular \\
\hline Spore & No & Yes \\
\hline Margin & Smooth & Rough \\
\hline Colour & Greenish colour & Slight yellow \\
\hline Elevation & Flat & Flat \\
\hline Opacity & Opaque & Opaque \\
\hline
\end{tabular}

\section{6s rRNA MICROBIAL IDENTIFICATION}

Sequence data obtained were aligned and dendrograms were generated using Sequence analysis software version 5.2 from Applied Biosystems. The 16SrRNA sequence of SS-A-1 and S-B-2 was subjected to homology analysis through Basic local alignment search tool (BLAST) at the NCBI server. The sequence showed extensive homologies with the Pseudomonas aeruginosa and Bacillus subtilis.

\section{OPTIMIZATION OF PHYSICAL PARAMETERS FOR MAXIMUM BACTERIAL GROWTH}

\section{Effect of $\mathrm{pH}$ on bacterial growth}

The optical density of the samples grown was spectrophotometrically analysed at $595 \mathrm{~nm}$ and $\mathrm{pH} 7$ was found to be optimum for both the organisms (Figure $3)$.

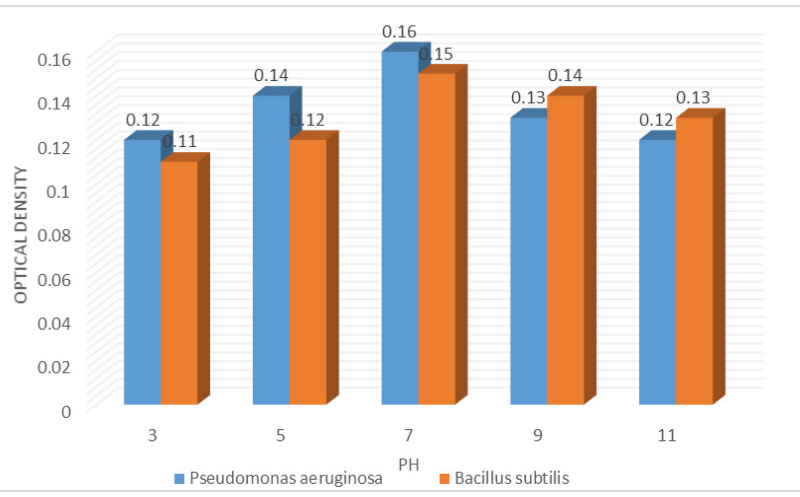

Figure 3: Effect of pH on bacterial growth. Microorganisms' showed an optimum $\mathrm{pH}$ of 7 .

\section{Effect of temperature on bacterial growth}

The optimum temperature for Bacillus subtilis was 
found to be $30^{\circ} \mathrm{C}$ and $37^{\circ} \mathrm{C}$ for Pseudomonas aeruginosa respectively (Figure 4).

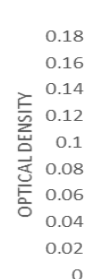
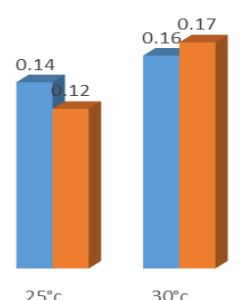

$30^{\circ} \mathrm{C}$

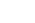

- Pseudomonas ae ruginosa = Bacillus subtilis

Figure 4: Effect of temperature on bacterial growth. Bacillus subtilis was found to be $30^{\circ} \mathrm{C}$ and

\section{Effect of carbon sources on PHB production:}

Glucose, maltose and fructose [1\%] were added as carbon sources. Among these three, glucose was found to be the best carbon sources from both Pseudomonas aeruginosa and Bacillus subtilis. The obtained powder was weighed using weighing balance (Figure 5).
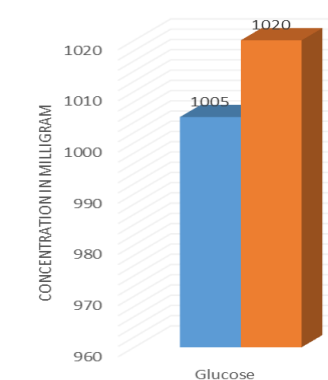

Glucose

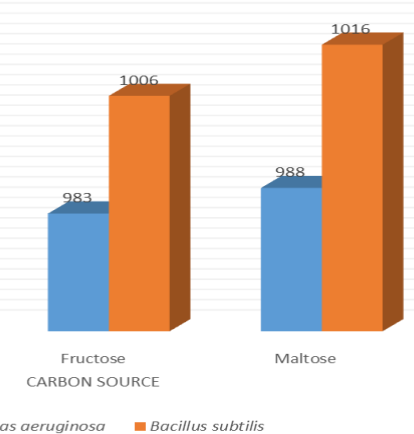

Figure 5 : Effect of carbon sources on PHB production where glucose is found to show optimum PHB production for both Pseudomonas aeruginosa and Bacillus subtilis.

\section{Effect of Nitrogen on PHB production}

Urea, Ammonium nitrate and Casein were added as nitrogen sources [1 \%] and it was found that Ammonium nitrate was best nitrogen source for Pseudomonas aeruginosa to produce PHB and urea for Bacillus subtilis (Figure 6).

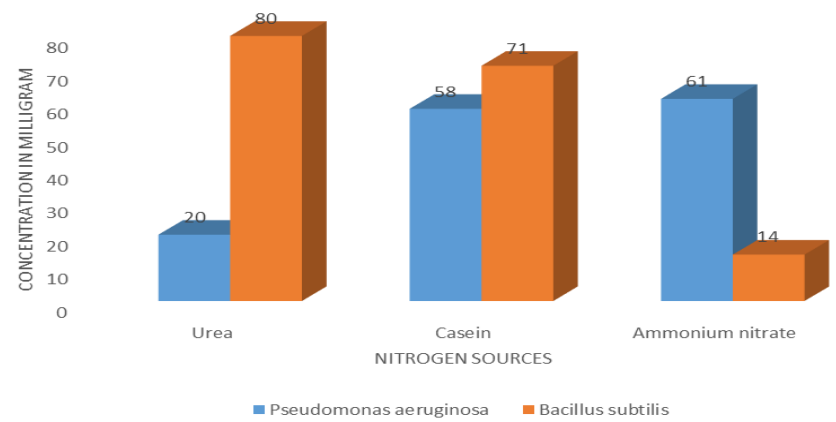

Figure 6: Effect of Nitrogen sources on PHB production where Ammonium nitrate is found to show optimum PHB production for Pseudomonas aeruginosa and Urea for Bacillus subtilis.

\section{MEDIA FORMULATION}

Species of Bacillus subtilis and Pseudomonas aeruginosa were able to produce PHB. Pseudomonas aeruginosa when optimized with glucose (carbon source) and Ammonium nitrate (nitrogen source), temperature $37^{\circ} \mathrm{C}$ and $\mathrm{pH} 7$ produced $570 \mathrm{mg}$ of PHB as compared to Bacillus subtilis optimized with glucose and Urea at temperature $30^{\circ} \mathrm{C}, \mathrm{pH} 7.0$ that gave an yield of $340 \mathrm{mg}$ of PHB.

\section{Conclusion}

The study was conducted in order to isolate novel PHB Producing bacterial strains among the isolates which were screened. Two bacterial strains were screened (Pseudomonas aeruginosa and Bacillus subtilis) to be positive for PHB production and later the culture parameters were optimized to improve PHB yield. The tests also showed that Pseudomonas aeruginosa yields more PHB than Bacillus subtilis in comparison. The present study has thus produced useful data on optimized conditions for the production of PHB that can be used as, a rapidly evolving substitute for synthetic plastics based on petroleum.

\section{References}

1. Geyer, Jambeck. (2017) Production, use, and fate of all plastics ever made. Law Sci. Adv 3: e1700782.

2. Rinku Verma et al. (2016). Toxic Pollutants from Plastic Waste- A Review. Procedia Environmental Sciences $35: 701-708$

3. Eriksen M, Lebreton LCM, Carson HS, Thiel M, Moore CJ, Borerro JC, et al. (2014) Plastic Pollution in the World's Oceans: More than 5 Trillion Plastic Pieces Weighing over 250,000 Tons Afloat at Sea. PLoS ONE 9(12): e111913. https://doi.org/10.1371/ journal.pone.0111913.

4. Averous, L. (2004). Biodegradable multiphase systems based on plasticized starch: a review. Journal of Macromolecular Science, Part C: Polymer Reviews, 44(3), 231-274.

5. Hernandez-Izquierdo, V. M., \& Krochta, J. M. (2008). Thermoplastic processing of proteins for film formation-a review. Journal of food science, 73(2), R30-R39.

6. Siracusa, V., Rocculi, P., Romani, S., \& Dalla Rosa, M. (2008). Biodegradable polymers for food packaging: a review. Trends in Food Science \& Technology, 19(12), 634-643.

7. Lemoigne, M. (1926). Products of dehydration and of polymerization of $\beta$-hydroxybutyric acid. Bull Soc Chem Biol, 8, 770-782.

8. Shang, L., Jiang, M. \& Chang, H.N. (2003) Poly (3-hydroxybutyrate) synthesis in fed-batch culture of 
Ralstonia eutropha with phosphate limitation under different glucose concentrations. Biotechnol Lett 25, 1415-1419.

9. Peters, V. \& Rehm, B.H.A. (2005) In vivo monitoring of PHA granule formation using GFP-labeled PHA synthases. FEMS Microbiol Lett 248, 93-100.

10. K.R.Shah (2014) Optimization and production of Polyhydroxybutyrate(PHB) by Bacillus subtilis G1S1from soil, ISSN: 2319-7706 Volume 3 Number 5 (2014) pp. 377-387.

11. Sunitha Panigrahi, Ujwala Badveli. (2013). Screening, Isolation and Quantification of PHBProducing Soil Bacteria. International Journal of Science Engineering and Invention. Volume 2 Issue 9.
12. Christina Thapa1, Pallavi Shakya1, Rabina Shrestha1, Sushovita Pal1, Prakash Manandhar. (2018). Isolation of Polyhydroxybutyrate (PHB) Producing Bacteria,Optimization of Culture Conditions for PHB production, Extraction and Characterization of PHB. Nepal Journal of Biotechnology. Volume 2.

13. Godale C, Ambarshetti S. (2015) Media optimization for Phb production and its application as precursor for bioplastics. European Journal of Biotechnology and Bioscience. 3(12):49-51.

14. S. Khannan, A.K. Srivastava. (2005). Recent advances in microbial poly-hydroxyalkanoates. Process Biochem., 40, 607-619. 